\title{
Nutrition-related histopathology of the intestine of milkfish Chanos chanos fry
}

\author{
Helmut Segner ${ }^{1}$, Patricia Burkhardt ${ }^{1}$, Enrique M. Avila ${ }^{1,2}$, \\ Jesus V. Juario ${ }^{2}$ \& Volker Storch ${ }^{1}$ \\ ${ }^{1}$ Zoologisches Institut der Universität Heidelberg, Im Neuenheimer Feld 230, D-6900 Heidelberg, Federal Republic of \\ Germany \\ ${ }^{2}$ Aquaculture Department, Southeast Asian Fisheries Development Center (SEAFDEC), Tigbauan, Iloilo, The Philippines
}

\begin{abstract}
A histopathological study was conducted on the intestine of milkfish larvae Chanos chanos, subjected to different nutritional conditions. Newly caught milkfish fry, ca $20 \mathrm{~d}$ old, were starved for $7 \mathrm{~d}$ and then fed with either Artemia nauplii or Chlorella sp. The latter diet, as already shown in other studies, is detrimental to young milkfish. A third, control, group of fry was starved for a further $2 \mathrm{~d}$. In larvae fed with Artemia, 1 to $2 \mathrm{~h}$ after feeding, intensive lipid absorption was noted in the first part of the intestine (Intestine I, lipid-absorbing zone, midgut). The second part of the intestine (Intestine II, hindgut) was characterized by pinocytotic activity and the presence of large supranuclear vacuoles. Food deprivation for 9 d resulted in cellular hydration, transformation of mitochondria, disturbances of the basal labyrinth and appearance of autolytic vacuoles in enterocyte cytoplasm in Intestine I, with a proximo-distal gradient of severity of enterocytic degeneration. In Intestine II, supranuclear vacuoles were replaced by dense bodies; pinocytotic activity was maintained at a reduced level. Microvilli were fragmented over the whole length of the intestine. Chlorella-fed larvae, although containing broken algae within the gut lumen, displayed no signs of nutrient absorption as detectable by electron microscopy. In Intestine I, enterocytes contained bizarre nuclei, an enhanced number of lysosomes and occasionally large intracellular vacuoles. In addition, intercellular spaces were dilated. Mitochondria appeared pale and swollen throughout the gut. Histological alterations in Intestine II were similar to those for starved fry.
\end{abstract}

\section{INTRODUCTION}

The digestive tract is among those organs, aside from the gills and the skin, whose surfaces are constantly exposed to the rigors of the environment (Peters 1981). Although the luminal milieu is different from the conditions prevailing in the external environment of a fish due to modifications brought about by its secretions, the environment may induce significant effects on the digestive tract. Structural modifications in the digestive tract epithelia may be a consequence of environmental effects such as food intake and digestion (e.g. Iwai 1969, Noaillac-Depeyre \& Gas 1974), osmoregulation (Nonotte et al. 1986) and social stress (Peters 1982, Willemse et al. 1984) together with the inherent properties of the tract. However, information upon histopathology of the intestinal tract of teleosts as related to environmental influences is scarce. In young fish, the digestive tract is easily affected by starvation, and histopathological changes accompanying such a condition are a good indicator of environmental quality (Ehrlich et al. 1976, O'Connell 1976, Theilacker 1978). While this is informative, histological changes induced by pure starvation should be distinguished from pathological changes induced by ingested material (Eckmann 1985). Our study was therefore designed to distinguish characteristics of intestinal pathology related to the lack of food and to the effects of ingesting inappropriate food.

The milkfish Chanos chanos is an ideal subject for this study as this species is economically important in many countries in Southeast Asia (Smith 1981). Moreover, despite its significance, little is known about its biology so that the subject merits investigation: For milkfish larval rearing, natural food such as rotifer Brachionus plicatilis or brine shrimp Artemia salina are mass produced using Chlorella virginica (Juario \& Duray 1982). Feeding milkfish larvae with 
Chlorella alone, however, results in high mortalities (Juario \& Storch 1984, Segner et al. 1987) indicating that this unicellular algae is not appropriate as a direct food for milkfish. Since the object of this study was to demonstrate the effects of poor food on the intestinal pathology of milkfish, Chlorella was used as a possible agent to cause signs distinguishable from starvation. For comparison, Artemia-fed milkfish were used since brine shrimp results in good growth and survival of young fish (Duray \& Bagarinao 1984, Segner \& Juario 1986).

\section{MATERLAL AND METHODS}

Fish. The milkfish fry (pterygiolarvae) used in this study were caught from a natural fry-collecting ground located in Hamtik, Antique, The Philippines and were transported to the laboratory site of the Aquaculture Department Southeast Asian Fisheries Development Center (SEAFDEC) in Tigbauan, lloilo. The fry were approximately $20 \mathrm{~d}$ old and of $7.08 \mathrm{mg}$ mean weight and $1.39 \pm 0.04 \mathrm{~cm}$ mean standard length at the time of capture. In the laboratory, the fry were randomly distributed into mildly aerated 201 glass aquaria, which were covered with black plastic sheets on the sides. Each aquarium contained 2 fry $l^{-1}$.

Water supplied to the aquaria was passed through a cartridge filter assembly having a mesh size of $60 \mu \mathrm{m}$ and maintained at a salinity of $34 \%$ and temperature range of 26 to $30^{\circ} \mathrm{C}$. Nine-tenths of the water volume in each aquarium was removed and refilled with newly filtered seawater each day throughout the duration of the experiment. The sides and bottom of each aquarium were thoroughly cleaned to prevent algal growth and accumulation of detritus.

Experimental design. All fry in the aquaria were starved for $7 \mathrm{~d}$, thereafter the first 2 groups were refed either with newly-hatched Artemia nauplii or Chlorella sp., and the 3rd group was starved for 2 further days. We used this starvation and refeeding schedule since, as shown by Storch et al. (1983), it may provide understanding of the nature of dietary action on cellular structures.

The brine shrimp used in the refeeding regime were freshly hatched nauplii from a Chinese strain and their chemical composition has already been reported by Duray \& Bagarinao (1984). Chlorella sp. was obtained from a cultured stock used for routine larval rearing in the SEAFDEC laboratory (Juario \& Duray 1982). At the time of feeding, caution was taken to avoid the Chlorella density introduced into the aquaria exceeding 100 to $150 \times 10^{4} \mathrm{cells} \mathrm{ml}^{-1}$. Feeds were introduced into the aquaria of the refed groups between 0800 and $0900 \mathrm{~h}$
Transmission electron microscopy. Sampling was carried out from the starved and refed groups on the second day of refeeding, 1 to $2 \mathrm{~h}$ after food was given. Particular attention was given to the time of fixation, since intestinal histology greatly changes with time after food ingestion.

Four specimens were retrieved from each aquarium. The larvae were cut into 3 parts and immersed in cold $2.5 \%$ glutaraldehyde in $0.1 \mathrm{M}$ Soerensen buffer at $\mathrm{pH} 7.5$ for $2 \mathrm{~h}$. These were then rinsed several times in the same buffer and postfixed for another $2 \mathrm{~h}$ in $1 \%$ osmium tetroxide in $0.1 \mathrm{M}$ Soerensen buffer at $\mathrm{pH} 7.3$. Samples were dehydrated in a graded series of ethanol and embedded in araldite.

The whole gut of a single specimen, from the esophagus to the anus, was divided into 46 planes of ultrathin sections with about 20 semithin sections in between. Ultrathin sections were stained with uranyl acetate and lead citrate prior to examination in the electron microscope. The semithin sections were stained according to the procedure of Richardson et al. (1960).

\section{RESULTS}

\section{Gross morphology of alimentary tract}

For all diets, no differences in gross morphology of the digestive tract of $9 \mathrm{~d}$ old milkfish fry were observed.

The complete histological differentiation of milkfish gut occurs between Day 6 to 9 of rearing ( 26 to $29 \mathrm{~d}$ posthatch) (Segner \& Juario 1986), although the intestine becomes longer and more intensively folded afterwards. The gut is composed of the following parts: (a) esophagus - this can be distinguished from other regions by multilayered ectodermal epithelium, a striated muscle layer and the presence of numerous mucous cells; (b) stomach, consisting of cardia, corpus (with gastric glands) and pyloric region (with a thick, smooth muscle layer and with appendices pyloricae); (c) intestine, which is subdivided into Intestine I (fatabsorbing zone), II (zone of supra-nuclear vacuoles) and III (rectum) (Fig. 1). All 3 parts are histologically distinct. The intestinal epithelium is made up nearly exclusively of columnar cells. Goblet cells are rare before metamorphosis. In the distal part of Intestine I and over the whole length of Intestine II cilia-bearing cells were observed. They often were arranged in groups of 2 to 4 . Such cells have been reported several times in teleosts (e.g. Odense \& Bishop 1966, Somasundaram et al. 1985) and may function to aid the very thin smooth muscle layers in food movement. Diet-related cytological changes of intestinal epithelial cells were 

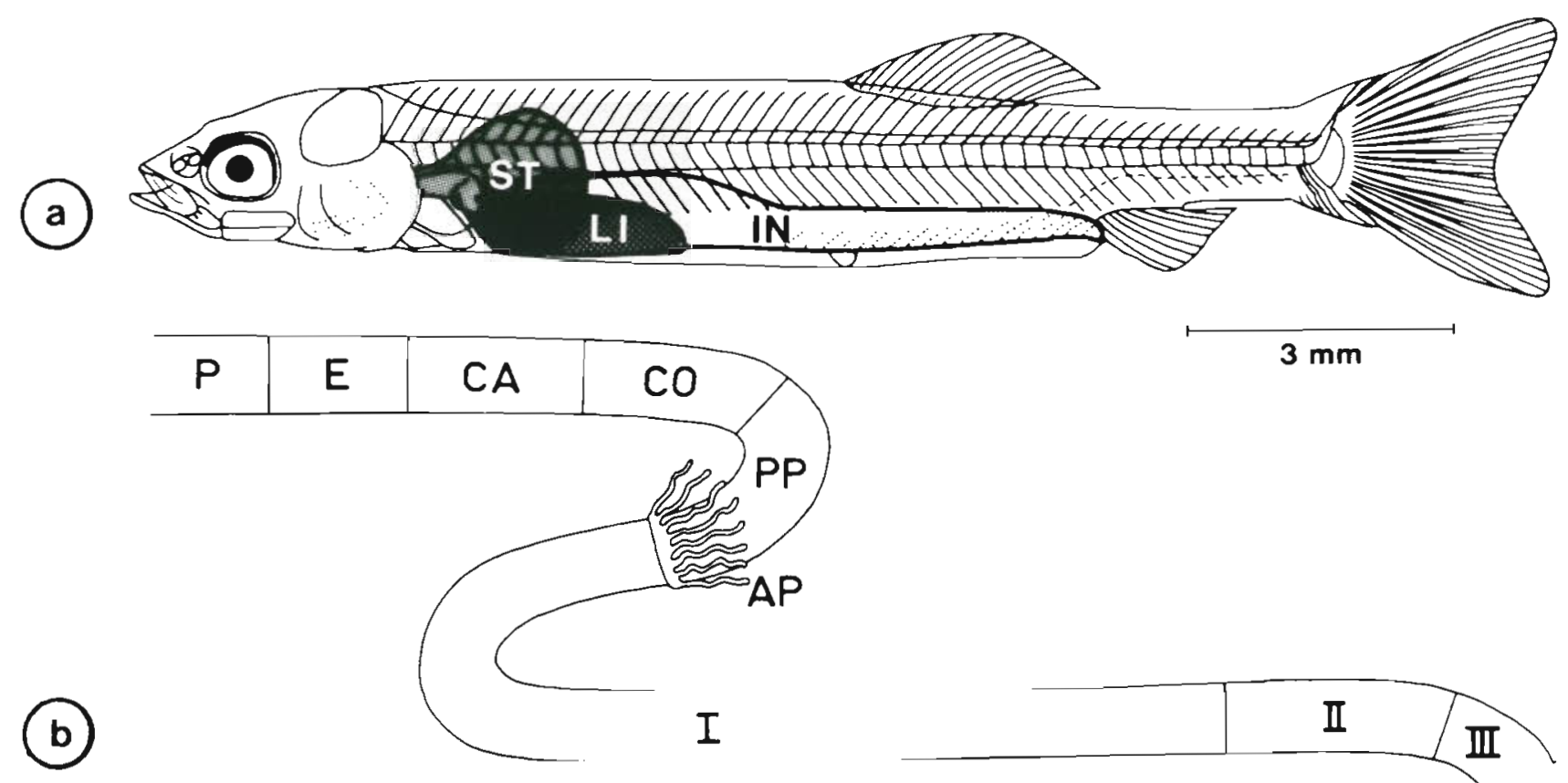

$3 \mathrm{~mm}$
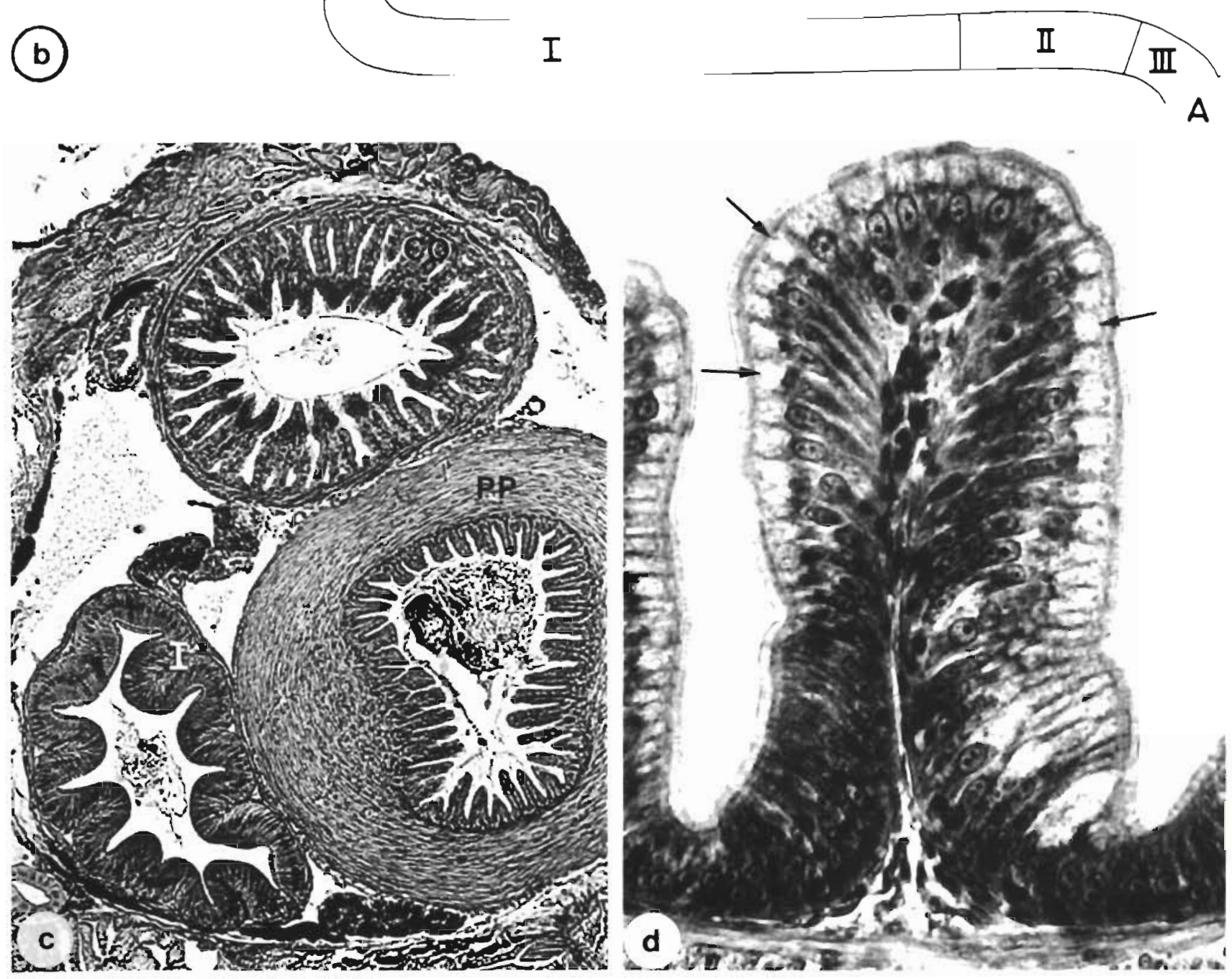

Fig. 1. Chanos chanos larvae. (a) Whole larva (ca 20 d old). (b) Schematic representation of the different parts of intestinal tract of milkfish fry $29 \mathrm{~d}$ old, fed with Artemia. (c) Transverse section of corpus, pars pyloricus and Intestine I in $29 \mathrm{~d}$ old milkfish fry fed with Artemia. Haematoxylin-eosin. $100 \times$. (d) Mucosal fold in Intestine II. Note vacuoles in the supranuclear parts of the enterocystes (arrows). Same specimen as in (c). Haematoxylin-eosin. 400x. ST: stomach; LI: liver; IN: intestine; P: pharynx; E: esophagus; CA: cardia; CO: corpus; PP: pars pyloricus; AP: appendices pyloricae; I, II, III: intestinal regions; A: anus 


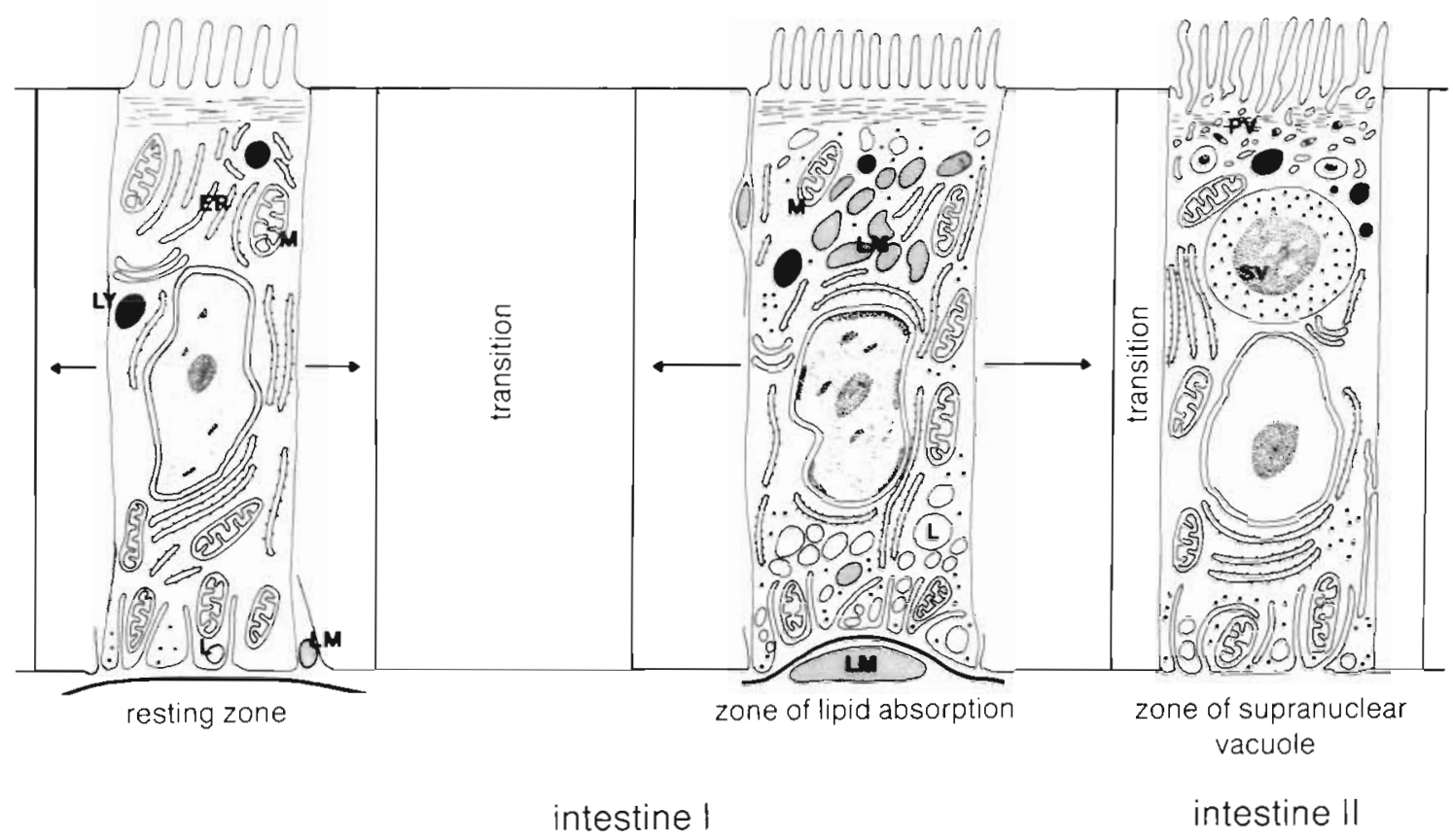

Fig. 2. Chanos chanos. Schematic representation of characteristic features of enterocytes of Artemia-fed milkfish fry. Relative length of each intestinal region is indicated by the vertical bars. In the 'resting zone', signs of on-going lipid absorption are absent. Lipid material is, however, deposited in the submucosa and intercellular spaces. For details see text. ER: endoplasmic reticulum; L: lipid droplet; LM; lipid material; LY: lysosome; M: mitochondrium; PV: pinocytotic vesicles; SV: supranuclear vacuole

limited essentially to Intestinal Regions I and II. Therefore, the following results will be confined to these regions, herein after referred to as Intestines I and II.

\section{Ultrastructure of enterocytes of Artemia-fed larvae}

General fine structure and organisation of enterocytes from milkfish intestine corresponded to features already described from other teleosts (Iwai 1969, Tanaka 1973, Noaillac-Depeyre \& Gas 1974, Burkhardt 1987). The most cranial part of Intestine I consisted of enterocytes which were characterized by a slightly basally oriented, elongated nucleus with a distinct nucleolus, but nearly no heterochromatin (Fig. 2). At cell apices, there were numerous mitochondria with electron-lucent matrices, rough and smooth endoplasmic reticulum ( $r E R, s E R)$ in form of short cisternae or vesicles, a varying number of heterogeneously structured lysosomes, and sometimes multivesicular bodies. Toward the nucleus, rER became more prominent and was arranged in parallel stacks. Dictyosomes were located in a perinuclear position. Between the lamellar infoldings of the basal cell membrane, higher numbers of mitochondria were found again, together with several small, membrane-bound lipid droplets and occasionally some single $\alpha$-glycogen-rosettes. Lamellar infoldings also originated from lateral cell membranes up to the height of the nucleus. Parts of intercellular space as well as the submucosa were filled with irregularly formed material of variable size and with amorphous, heterogeneous, slightly osmiophilic matrices (Fig. 3a, b), indicating their lipid nature.

Behind the cranial part of Intestine I, a transition took place among the enterocytes which showed signs of intensive lipid absorption. Cell apices were filled

Fig. 3. Chanos chanos larvae. Transmission electron micrographs of intestine. (a) Fry refed for $2 \mathrm{~d}$ with Artemia. Apical parts of enterocytes in Intestine I are filled with heterogeneous slightly osmiophilic amorphous lipid granules ( $\star$ ), delimited by a smooth membrane. $7800 \times$. (b) Fry refed for $2 \mathrm{~d}$ with Artemia. Slightly osmiophilic lipid material predominates in intercellular spaces and submucosa. In the basal part of the enterocytes homogeneous lipid droplets abound. $4000 \times$. (c) Fry starved for $9 \mathrm{~d}$. Characteristic starvation signs in Intestine I: fragmentation of microvilli and occurrence of autolytic vacuoles. $3100 x$. (d) Fry refed for $2 \mathrm{~d}$ with Chlorella. Large vacuoles in epithelial cells and prominent extensions of intercellular spaces present in distinct parts of Intestine I. $7800 \times$. (e) Fry refed for $2 \mathrm{~d}$ with Artemia. Typical supranuclear vacuoles of Intestine II. Arrows: zone of pinocytosis. $4600 x$. (f) Fry starved for $9 \mathrm{~d}$. Fragmented microvilli. Supranuclear vacuoles replaced by large dense bodies Identical features also observed in Chlorella-fed specimens. 4600x. L: lipid droplet; AV: autolytic vacuole; V: vacuoles; SV: supranuclear vacuole 

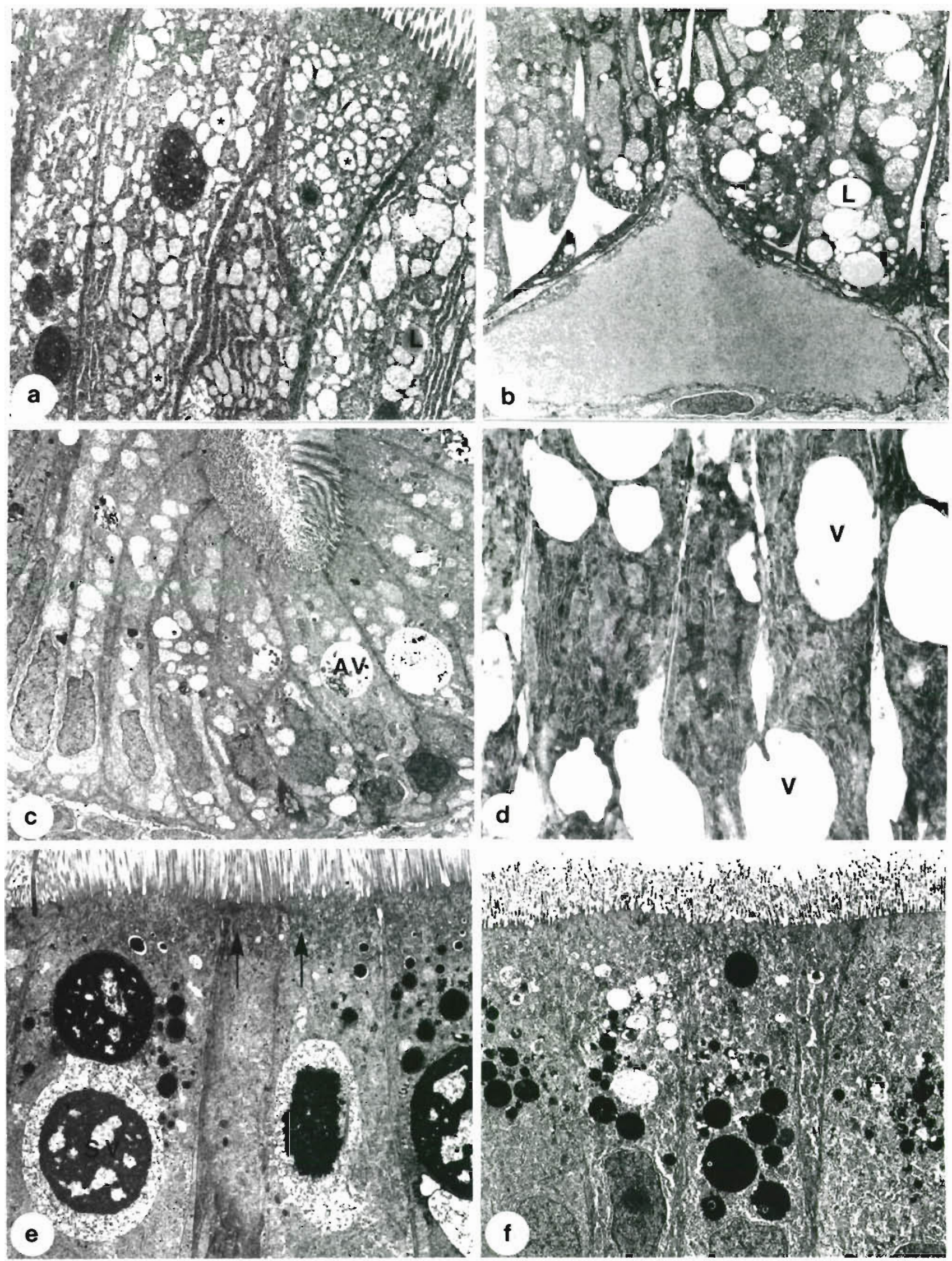
with slightly osmiophilic vesicles of greatly varying size. Their amorphous and heterogeneous matrices had the same appearance as already described for the material in the extracellular space of the most cranial part of Intestine I (Fig. 3a, b). These apical lipid granules were surrounded by a smooth membrane. The whole reticular and Golgi structures of supranuclear cytoplasm contained amorphous lipid material. In addition, a few small droplets with homogeneous lipid material (Fig. 3b) and somewhat enhanced electron density were stored (Fig. 3a). The droplets were most frequent in the basal part of the cells where the amorphous lipid material was rare. In the intercellular space and in the submucosa was a massive infiltration of amorphous lipid material (Fig. 3b). The gut lumen was filled with partly digested food materials.

Most prominent in Intestine II were the supranuclear vacuoles. Their morphology and size were variable. Usually the vacuoles consisted of dark, electron-dense centers and electron-lucent halos; the latter containing glycogen-like particles. The matrices of the centers were heterogeneous. The intermicrovillous plasma membrane was deeply invaginated into the apical cytoplasm to form pinocytotic vesicles, some of which were confluent with intracellular vacuoles. Whole apical cytoplasm was crowded with small vacuoles, spherical or irregular in shape. The vacuoles increased in size toward the nucleus and often contained electrondense granula. Larger, strongly electron-dense bodies were closely associated with the supranuclear vacuole (Fig. 3e). The other cell structures of epithelial cells of the posterior gut were similar in their general features to those of Intestine $I_{1}$ except that they contained much less lipid.

\section{Ultrastructure of enterocytes of starved larvae}

In the region of Intestine I next to the distal end of the stomach, severe degenerative alterations were evident (Fig. 4a). There was a hydration of cellular apices and a fragmentation of microvilli into microblebs. Mitochondria were heavily swollen and the number and depth of cristae were reduced. The basal part of the enterocytes showed no hydropic swelling. The number of lamellar infoldings of the basal labyrinth was reduced and often their spatial organization was disturbed. Generally the cells possessed only few organelles and practically no stored products. Occasionally large autolytic vacuoles containing electrondense debris were observed (Fig. 3c). Intercellular spaces and submucosa were free of lipid material. In addition to the hydropic enterocytes, a smaller percentage of shrunken, electron-dense cells were found in the intestinal epithelium.
In the following sections of Intestine I, the cell integrity was better preserved than in the first part. Hydropic swelling or spherical transformation of mitochondria was absent. However, vesiculation of microvilli persisted. Whereas the number of lysosomes increased, the number of other organelles was reduced. Cisternae of $\mathrm{IER}$ were fragmented into vesicles. Again, the lamellae of the basal labyrinth were few and disorganized. Glycogen was totally absent. A very small number of quite electron-dense lipid droplets were found in the basal parts of the cells.

The most apparent difference of Intestine II in starved larvae compared to the Artemia-fed larvae was the absence of a typical supranuclear vacuole. Instead, the apical parts of the cells were occupied by aggregations of electron-dense bodies. Their diameter sometimes nearly reached that of a supranuclear vacuole. The number of tubular infoldings of the intermicrovillous plasma membrane as well as the number of apical vesicles and vacuoles was reduced (Fig. 3f).

\section{Ultrastructure of enterocytes of Chlorella-fed larvae}

In Chlorella-fed specimens, Intestine I reacted homogeneously over its total length. The gut lumen was filled with intact algae as well as algae with broken cell walls. Microvilli and basal labyrinth were not changed compared to the Artemia-fed larvae (Fig. 4b). The nuclei were often bizarre and showed a condensed caryoplasm. Perinuclear cisternae could be dilated. The rER was better developed than in the starved larvae, but less than in Artemia-fed larvae. The cisternae were broken into vesicles and dilated. The somewhat irregularly formed or even branched mitochondria were large and had electron-lucent matrices. There was a higher number of lysosome bodies, not only in the apical parts of the cell, but also in the basal parts. Sometimes they contained crystal-like inclusions. Few lipid droplets, located basally to the nucleus, occurred. All signs of lipid absorption as described for Artemia-fed fish were lacking.

A peculiar characteristic of Chlorella feeding was the presence of vacuoles in epithelial cells and large, dilated intercellular spaces in distinct parts of Intestine I (Fig. 3d). The morphology of the vacuoles was clearly different from the autolytic vacuoles found in starved specimens. In cross sections, a limiting membrane could be detected in some cases, but there were also vacuoles without a surrounding membrane. In Intestine II, as in the starving larvae, the supranuclear vacuole was replaced by electron-dense bodies. Pinocytotic activity at cell apices was more pronounced than in starved larvae. 

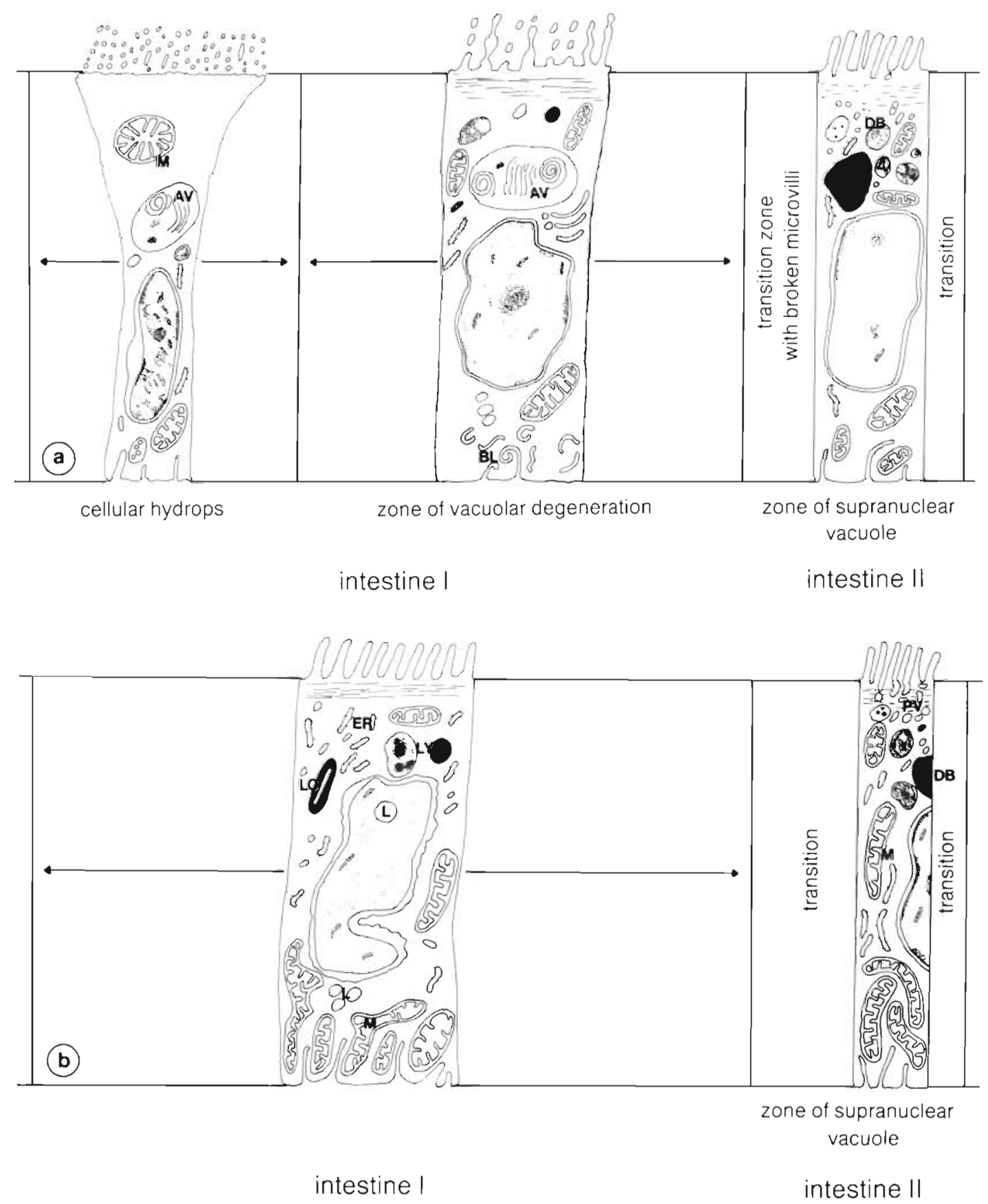

Fig. 4. Chanos chanos. Schematic representation of characteristic features of enterocytes of milkfish fry under different nutritional conditions. Line drawing reduced true to scale. For details see text. (a) Starved milkfish fry. Note severeness of pathological cell degeneration in a cranio-caudad direction. (b) Chlorella-fed milkfish fry. Note in (a) and (b) that the zone of supranuclear vacuole is shorter than in Artemia-fed specimens (Fig. 2). AV: autolytic vacuole; BL: basal labyrinth; DB: dense body; M: mitochondrium; ER: endoplasmic reticulum; L: lipid droplet; LC: lysosome with crystalline-like inclusion; LY: lysosome; PV: pinocytotic vesicles

\section{DISCUSSION}

Previously starved milkfish larvae, when refed with Artemia, showed intensive lipid absorption in Intestine I and prominent supranuclear vacuoles in Intes- tine II. This can be considered as the 'normal' state of enterocyte ultrastructure in milkfish intestinal tract during absorption.

Lipid absorption in the intestine and its subsequent transfer to the body tissues in fish does not differ 
fundamentally from that of mammals (Bauermeister et al. 1979, Sire et al. 1981). Epithelial cells of the proximal part of the intestine take up alimentary fat by diffusion of a micellar form of monoglyceride and fatty acids after intraluminal hydrolysis (Sire et al. 1981, Yamamoto 1982). Resynthesis of triglycerides occurs in the smooth endoplasmic reticulum. These triacylglycerols are transported through the Golgi complex and released into the intercellular spaces or stored temporarily as lipid droplets in the cytoplasm of the enterocytes. Most authors agree that lipid is finally discharged into the submucosa as chylomicron-like particles (Stroband \& Debets 1978, Bauermeister et al. 1979, Hatae et al. 1986). Our findings on the ultrastructural features of lipid absorption in Intestine I of Artemia-fed milkfish larvae fit well into this scheme.

In Intestine II, Artemia-feeding resulted in highly active pinocytosis and well-developed supranuclear vacuoles. These features are typical of the hindgut region of feeding teleost larvae (Tanaka 1973, Stroband \& Kroon 1981, Watanabe 1982, Govoni et al. 1986)

In contrast to Artemia, Chlorella is clearly inadequate for larval milkfish. This is evidenced by the results on liver histology and on larval survival (Juario \& Storch 1984, Segner et al. 1987) as well as by the findings of this study, in which Chlorella evoked severe degeneration of the intestinal tract.

Some lesions of the teleost intestine are likely to occur frequently in pathological cases since these have been found among different species under a spectrum of environmental conditions. These were observed again in the starved and Chlorella-fed milkfish larvae: reduction of absorptive surface by regression or distortion of microvilli (Gas \& Noaillac-Depeyre 1976 starved milkfish larvae); widening of intercellular spaces and loosening of cell contacts (O'Connell 1976, Theilacker 1978, Peters 1982, Nonotte et al. 1986 Chlorella-fed milkfish larvae); swelling of mitochondria and dilation of reticular system (Gas \& NoaillacDepeyre 1976, Peters 1982, Somasundaram et al. 1985 - starved and Chlorella-fed milkfish larvae); vacuolization (Peters 1982, Eckmann 1985 - Chlorella-fed milkfish larvae); autophagic processes (Gas \& Noaillac-Depeyre 1976, Peters 1982 - starved milkfish larvae); size reduction and disappearance of supranuclear vacuole, decrease in number of intermicrovillous invaginations (O'Connell 1976, Theilacker 1978, Iida \& Yamamoto 1984 - starved and Chlorella-fed milkfish larvae).

Despite the obvious uniformity in the potential reaction possibilities of the teleostean gut, pathological response of Chlorella-fed milkfish larvae was clearly distinguishable from starvation response, because of a diet-specific combination of the pathological features.
Juario \& Storch (1984) as well as Segner et al. (1987) found starvation-like symptoms in the liver of Chlorella-fed milkfish larvae. In this study, no indications of nutrient absorption across the intestinal epithelium of Chlorella-fed fry could be detected by means of electron microscopy. Nevertheless, the present histopathological findings upon the gut suggest that of Chlorella action is different from that of food deprivation.

The Chlorella-related intestinal alterations are associated with heavy mortalities among the milkfish fry, as demonstrated by Segner et al. (1987) in a continuous feeding experiment $1100 \%$ mortality within $6 \mathrm{~d}$ of feeding). Fry mortality in the Chlorella-fed group occurred demonstrably earlier than in the starved control group ( $100 \%$ mortality within $12 \mathrm{~d}$ ). An identical phenomenon was reported by Eckmann (1985): feeding coregonid larvae with zooplankton from Lake Constance resulted in serious degenerative changes of the intestinal epithelium and, at the same time, in mass mortalities among the larvae. Because these mortalities occurred earlier than losses among starved larvae, the author concluded that the zooplankton was the causative agent for larval mortality and intestinal degeneration.

Findings such as those of Eckmann (1985), as well as those from the present study, stress the importance of a well-developed 'healthy' intestinal morphology for survival and well-being of fish larvae. The larval alimentary tract, which is less elaborate than that of the adults (Govoni et al. 1986) may be particularly vulnerable to inadequate nutritional conditions. Further investigations presently under way in our laboratory will, we hope, elucidate more details on morphological changes of the teleostean gut in relation to nutrition impact, e.g. dietary value and digestibility of food. As such, the basis for understanding the functional processes of food digestion and nutrient absorption in the alimentary tract of teleosts will be laid out.

Acknowledgement. The authors are indebted to Ms R. Mummert for intensive technical assistance.

\section{LITERATURE CITED}

Bauermeister, A. E. M., Pirie, B. J. S., Sargent, J. R. (1979). An electron microscopic study of lipid absorption in the pyloric caeca of rainbow trout (Salmo gairdneri) fed wax ester-rich zooplankton. Cell Tissue Res. 200: 475-486

Burkhardt, P. (1987). Elektronenmikroskopische Untersuchungen am Darmkanal von Leuciscus idus melanotus und Poecilia reticulata. Z. mikrosk. anat. Forsch. Leipzig, in press

Duray, M., Bagarinao, T. (1984). Weaning of hatchery-bred milkfish larvae from live food to artificial diets. Aquaculture 41: 325-332

Eckmann, R. (1985). Histopathological alterations in the intestine of whitefish (Coregonus sp.) larvae reared on 
zooplankton from Lake Constance. Dis. aquat. Org. 1 $11-17$

Ehrlich, K. F., Blaxter, J. H. S., Pemberton, R. (1976). Morphological and histological changes during the growth and starvation of herring and plaice larvae. Mar. Biol. 35 $105-118$

Gas, N., Noaillac-Depeyre, J. (1976). Studies on intestinal epithelium involution during prolonged fasting. J. Ultrastruct. Res. 56: 137-151

Govoni, J. J., Boehlert, G. W., Watanabe, Y (1986). The physiology of digestion in fish. Env. Biol. Fish. 16: 59--77

Hatae, T., Fujita, M., Yamamoto, T (1986). Membrane differentiation in the cytoplasmic tubule system of the intestinal absorptive system of the lamprey, Lampetra japonica. Cell Tissue Res. 243: 461-468

Iida, H., Yamamoto, T. (1984). Morphological studies of the goldfish hindgut mucosa in organ culture. Cell Tissue Res. 238: $523-528$

Iwai, T. (1969). Fine structure of the gut epithelial cells of larval and juvenile carp during absorption of fat and protein. Arch. histol. jap. 30: 183-199

Juario, J. V., Duray, M. N. (1982). A guide to induced spawning and larval rearing of milkfish, Chanos chanos (Forsskal). SEAFDEC Technical Report No. 10

Juario, J. V., Storch, V. (1984). Biological evaluation of phytoplankton (Chlorella sp., Tetraselmis sp. and Isochrysis galbana) as food for milkfish (Chanos chanos) fry. Aquaculture 40: 193-198

Noaillac-Depeyre, J., Gas, N. (1974). Fat absorption by the enterocytes of the carp (Cyprinus carpio L.). Cell Tissue Res. 155: 353-365

Nonotte, L., Nonotte, G., Leray, G. (1986). Morphological changes in the middle intestine of the rainbow trout, Salmo gairdneri, induced by a hyperosmotic environment. Cell Tissue Res. 243: 619-628

O'Connell, C. P. (1976). Histological criteria for diagnosing the starving conditions in early post yolk sac larvae of the northern anchovy, Engraulis mordax Girard. J. exp. mar Biol. Ecol. 25: 285-312

Odense, H., Bishop, M. (1966). The ultrastructure of the epithelial border of the ileum, pyloric caeca and rectum of the cod, Gadus morrhua. J. Fish. Res. Bd Can. 23: 1841-1843

Peters, G. (1982). The effect of stress on the stomach of the European eel, Anguilla anguilla L. J. Fish Biol. 21: 497-512

Peters, N. (1981). Fischkrankheiten und Gewässerbelastung im Küstenbereich. Verh. dt. zool. Ges. 16
Richardson, K. C., Jarett, L., Finke, E. H. (1960). Embedding in epoxy resins for ultrathin sectioning in electron microscopy. Stain Technol. 35: 313-325

Segner, H., Juario, J. V. (1986). Histological observations on the rearing of milkfish, Chanos chanos, fry using different diets. J. appl. Ichthyol. 2: 162-173

Segner, H., Burkhardt, P., Avila, E. M., Storch, V., Juario, J. V (1987). Histopathology of Chlorella-feeding in larval milkfish, Chanos chanos. Aquaculture (in press)

Sire, M. F., Lutton, C., Vernier, J. M. (1981). New views on intestinal absorption of lipids in teleostean fishes: an ultrastructural and biochemical study in the rainbow trout. J. Lipid Res. 22: 81-94

Smith, I. R. (1981). The economics of the milkfish fry and fingerlings industry of the Philippines. ICLARM Technical Reports No. 1, Manila

Somasundaram, B., King, P. E., Shackley, S. E. (1985). The effect of zinc on the ultrastructure of the posterior gut and pronephric ducts of the larva of Clupea harengus L. Comp. Biochem. Physiol. 81 C: 29-37

Storch, V., Stählin, W., Juario, J. V. (1983). Effects of different diets on the ultrastructure of hepatocytes of Chanos chanos fry: an electron microscopic and morphometric analysis. Mar. Biol. 74: 101-104

Stroband, H. W. J., Debets, F. M. H. (1978). The ultrastructure and renewal of the intestinal epithelium of the juvenile grasscarp (Ctenopharyngodon idella Val.). Cell Tissue Res. 187: 181-200

Stroband, H. W. M., Kroon, A. (1981). The development of the stomach in Clarias lazera and the intestinal absorption of protein macromolecules. Cell Tissue Res. 215: 397-415

Tanaka, M. (1973). Studies on the structure and function of the digestive system of teleost larvae. Ph. D. thesis, Faculty of Agriculture, Kyoto University, Japan

Theilacker, G. H. (1978). Effect of starvation on the histological and morphological characteristics of jack mackerel Trachurus symmetricus larvae. Fish. Bull. U.S. 76: 403-414

Watanabe, Y. (1982). Ultrastructure of epithelial cells of the anteromedian intestine and the rectum in larval and juvenile teleosts. Bull. Fac. Fish. Hokkaido Univ. 33: $217-228$

Willemse, J. J., Markus-Silvis, L., Ketting, G. H. (1984). Morphological effects of stress in cultured elvers, Anguilla anguilla (L.) Aquaculture 36: 193-201

Yamamoto, $T$ (1982). Ultrastructural basis of intestinal absorption. A.ch. histol. jap. 45: 1-22 